\title{
NUTRIÇÃO PARA IDOSOS
}

NUTRITION FOR THE ELDERLY

\author{
Vanessa Silva Tramontino * \\ Juliana Maria Costa Nuñez ${ }^{*+*}$ \\ Célia Marisa Rizzatti-Barbosa
} Jessica Mie Ferreira Koyama Takahashi ${ }^{* *}$ Claudia Batitucci dos Santos-Daroz

\section{RESUMO}

Este artigo tem por objetivo discutir a contribuição da nutrição na qualidade vida dos indivíduos idosos e de que forma ela pode influenciar para uma velhice mais saudável. Serão abordados os aspectos bioquímicos e fisiológicos do envelhecimento, os aspectos relacionados à saúde bucal e às necessidades nutricionais dos idosos, assim como serão evidenciadas as alterações fisiológicas que direta ou indiretamente afetam a sua alimentação.

DESCRITORES: Envelhecimento • Nutrição do idoso • Qualidade de vida.

\section{ABSTRACT}

The main of this article is to discuss the influence of nutrition in the orderly's quality of life and whether it can implicate in oral health or to contribute for a healthier old age. Considerations on biochemical and physiologic aspects of the aging will be considered, associated with the senior's nutritional needs, as well as it will be evidenced the physiologic changes that directly or indirectly affect elder food consumption.

DESCRIPTORS: Aging • Elderly Nutrition • Quality of life.

\footnotetext{
* Doutoranda em Clínica Odontológica - Área de Prótese Dental (Faculdade de Odontologia de Piracicaba - Universidade Estadual de Campinas)

** Mestranda em Clínica Odontológica - Área de Prótese Dental (Faculdade de Odontologia de Piracicaba - Universidade Estadual de Campinas)

*** Doutoranda em Clínica Odontológica - Área de Odontologia Restauradora (Faculdade de Odontologia de Piracicaba - Universidade Estadual de Campinas)

**** Professora Titular da Área de Prótese Parcial Removível (Faculdade de Odontologia de Piracicaba - Universidade Estadual de Campinas)
} 
Tramontino VS, Nuñez JMC, Takahashi JMFK, Santos-Daroz CB, Rizzatti-Barbosa CM. Nutrição para idosos. Revista de Odontologia da Universidade Cidade de São Paulo 2009 set-dez; 21(3): 258-67

\section{INTRODUÇÃO}

O envelhecimento é um processo fisiológico natural (Salgado ${ }^{25}$ 2002), que pode ser desenrolado de diversas formas em função da genética do indivíduo e do estilo de vida ao qual a pessoa se expôs durante a vida. Nas três últimas décadas observou-se um aumento de 85,5\% de pessoas com a idade de 65 anos ou mais e de 225\% na população de 85 anos ou mais (Barroso 5 2005). Isso devido, principalmente, aos avanços da medicina e às alterações no estilo de vida dos indivíduos. Dessa forma, o interesse no entendimento do processo de envelhecimento tem aumentado aceleradamente, não somente pelo aumento da população idosa, mas pela percepção de que se pode levar uma vida feliz, ativa e produtiva na etapa que outrora fora a pacata idade da aposentadoria (Knigth ${ }^{15}$ 2000). Assim, a consciência de que um estilo de vida saudável influencia na qualidade do envelhecimento tem feito com que, diariamente, mais pessoas adiram a práticas mais saudáveis, como o exercício físico e a melhor qualidade da dieta. Dentre os fatores ambientais, a nutrição desempenha papel proeminente, afetando uma variedade de processos degenerativos relacionados à idade (Wenzel ${ }^{31}$ 2006). A velhice prematura é causada muitas vezes pelos erros e absurdos da má alimentaçáo (Salgado ${ }^{25}$ 2002). Há estudos com culturas de células humanas que mostram que uma célula perde sua capacidade proliferativa ao redor dos 120 anos (Salgado ${ }^{25}$ 2002), o que leva a crer que, em condições saudáveis de vida, uma pessoa poderia atingir essa idade, morrendo devido à velhice e não às doenças. Há relatos de comunidades cujos habitantes apresentam idades entre $100 \mathrm{e}$ 130 anos, devido principalmente aos hábitos moderados, como a vida ao ar livre e a alimentação balanceada sem excessos (Salgado ${ }^{25}$ 2002).

Dessa forma, o objetivo deste artigo é discutir de que forma a nutrição pode influenciar na qualidade do envelhecimento humano.

\section{Aspectos bioquímicos do envelhecimento}

O envelhecimento é um processo multifatorial extremamente complexo (Wenzel ${ }^{31}$ 2006). Há mais de 300 teorias para explicar o fenômeno do envelhecimento. A maioria delas tem origem no estudo das alteraçóes que se acumulam com o tempo (Ashok ${ }^{4}$ 1999). O envelhecimento normal tem início ao final da fase de crescimento (Salgado ${ }^{25}$ 2002). Nessa etapa atinge-se a maturidade fisiológica e os processos catabólicos (de quebra de moléculas) superam os anabólicos (de síntese de moléculas), levando a uma diminuição no número de células e a uma consequente diminuição na função dos órgãos. Quanto maior o número de células mortas num tecido, e esse é um processo acumulativo, menor a função exercida pelo órgão correspondente.

Há diversas alteraçóes bioquímicas que levam à morte celular e ao consequente envelhecimento, sendo a glicosilação de proteínas, os defeitos no DNA e a ação dos radicais livres as mais destacadas.

A glicosilação das proteínas ocorre quando moléculas de glicose aderem e se entrelaçam às moléculas protéicas, fazendo com que estas percam sua estrutura e consequentemente sua função. As moléculas entrelaçadas são denominadas AGE (Advanced Glycation Age products) e são formadas após meses ou anos de aderência das moléculas de glicose. As AGE são associadas ao envelhecimento e a várias doenças relacionadas ao estresse oxidativo, como diabetes e suas complicações (Ames ${ }^{3}$ 2008), além de serem relacionadas à morte neuronal que ocorre em doenças degenerativas (como o mal de Parkinson e o mal de Alzheimer) e fazem com que este organismo produza até 50 vezes mais radicais livres em relação àquele com proteínas não glicadas (Guimarães ${ }^{12}$ 2002). Essa última afirmação pode explicar a redução no tempo de vida dos indivíduos diabéticos.

Os defeitos causados ao DNA celular ocorrem, principalmente, em 3 momentos: durante sua duplicação, durante a transcriçáo do RNA ou devido ao ataque dos radicais livres (Guimarães ${ }^{12}$ 2002, Hayashi ${ }^{14}$ 2002). A susceptibilidade de defeitos durante os dois primeiros processos é aumentada devido à separação da fita dupla do DNA. Erros podem ocorrer no retorno à posiçâo inicial das fitas, dando origem a uma molécula defeituosa.

Essa molécula defeituosa consequentemente altera o funcionamento dos genes, das moléculas proteicas e o mecanismo celular, levando à deterioração dos tecidos e dos órgãos correspondentes (Guimarães ${ }^{12} 2002$ ).

Os radicais livres são moléculas com um elétron não pareado, altamente reativo (Almada-Filho ${ }^{2}$ 2002), que tende a combinar-se e reduzir elétrons de outras moléculas, que se tornam instáveis e tendem a combinar-se com outras, formando uma reação em cadeia (Guimarães ${ }^{12}$ 2002). Os radicais livres são formados principalmente durante a respiração celular, processo pelo qual a célula humana produz energia. Nesse processo, que ocorre no interior da mitocôndria, há consumo de uma molécula de $\mathrm{O} 2$ e a produção de duas moléculas de $\mathrm{H} 2 \mathrm{O}$.

Quando há erros nesse processo, ao invés da produ- 
Tramontino VS, Nuñez JMC, Takahashi JMFK, Santos-Daroz CB, Rizzatti-Barbosa CM. Nutrição para idosos. Revista de Odontologia da Universidade Cidade de São Paulo 2009 set-dez; 21(3): 258-67

ção de moléculas de água podem ser formados radicais livres (Bianchi ${ }^{7}$ 1999), como o ânion superóxido (O2-), o peróxido de hidrogênio $(\mathrm{H} 2 \mathrm{O} 2)$ ou o radical hidroxila $(\mathrm{OH}-)$, que promoverão danos oxidativos às estruturas celulares. Dentre os principais processos oxidativos, estáo a peroxidação lipídica, os danos ao DNA e às mitocôndrias e as alteraçôes enzimáticas. Durante o processo de peroxidação lipídica, fatores quimiotáticos são liberados no local, atraindo leucócitos, que, por sua vez, liberam mais fatores quimiotáticos, estimulando a perpetuação do processo (Almada-Filho ${ }^{2}$ 2002). Os radicais livres, de uma forma geral, são diretamente relacionados à morte celular e aos consequentes transtornos relativos ao envelhecimento, como a doença de Alzheimer, de Parkinson, as osteoartrites, a catarata, as cardiopatias, a arteriosclerose, os problemas pulmonares e o câncer (Bianchi ${ }^{7}$ 1999, Biesalk ${ }^{8}$ 2002, Vanitalie ${ }^{29}$ 2008).

A ação dos radicais livres e sua produção são altamente influenciadas pela alimentação. Dessa forma, uma alimentação rica em substâncias antioxidantes pode favorecer a longevidade, diminuindo o risco de várias doenças humanas (Bianchi ${ }^{7}$ 1999) e, portanto, reduzindo a taxa de morte celular. Antioxidantes são quaisquer substâncias que, presentes em baixas concentraçóes quando comparadas às do substrato oxidável, atrasam ou inibem a oxidação desse substrato de maneira eficaz (Sies ${ }^{27}$ 1995). São agentes responsáveis pela inibição e redução das lesóes celulares causadas por radicais livres (Bianchi ${ }^{7}$ 1999). No organismo humano há enzimas com atividade antioxidante, como a catalase, a superóxido dismutase, a glutationa peroxidase e a glutationa redutase (Almada- Filho ${ }^{2}$ 2002, Knigth ${ }^{15}$ 2000, Bianchi ${ }^{7}$ 1999). Porém, para que haja redução na produção e na atividade dos radicais livres é importante que se adquiram antioxidantes provenientes da dieta. Os principais são a vitamina $\mathrm{E}$, a vitamina $\mathrm{C}$ e os betacarotenoides (Almada-Filho ${ }^{2}$ 2002, Bianchi $^{7}$ 1999, Sies ${ }^{27}$ 1995, Sahni et al. ${ }^{24}$ 2008, Boothby e Doering ${ }^{9}$ 2005, Lonn e Yusuf ${ }^{17}$ 1997, Weber ${ }^{30} 2006$, Pham e Plakogiannis ${ }^{23}$ 2005).

A vitamina $C$, encontrada principalmente em frutas cítricas, como a laranja, o limão, a acerola, dentre outras, além de ser uma excelente substância antioxidante, é essencial para a formação do colágeno e do desenvolvimento ósseo (Sahni et al. ${ }^{24}$ 2008). Quando combinada com a vitamina $\mathrm{E}$, tem seu papel antioxidante aumentado (Salgado ${ }^{25}$ 2002) e reduzem a prevalência de $\mathrm{Al}$ zheimer (Boothby e Doering9 2005). Um estudo recente mostrou que concentraçóes elevadas de vitamina $\mathrm{C}$ no plasma humano levaram à redução de $20 \%$ nas taxas de mortalidade geral, mostrando o papel benéfico desta vitamina (Khaw et al. ${ }^{15}$ 2001).

A vitamina $E$, que é encontrada sobretudo em cereais integrais, verduras, azeite e vegetais, apresenta importante papel antioxidante, impedindo a peroxidação lipídica (Almada-Filho ${ }^{2}$ 2002). Esta vitamina exerce importante função na estimulação da resposta imunológica e na inibição da formação de moléculas produtoras de tumores. Há estudos que relacionam a ingestão de vitamina $\mathrm{E}$ à redução de incidência de risco cardiovascular (Lonn e Yusuf ${ }^{17}$ 1997), ao retardo da progressão de demências já instaladas, como a doença de Parkinson (Weber ${ }^{30} 2006$ ) e a de Alzheimer (Pham e Plakogiannis ${ }^{23}$ 2005) e ao aumento da capacidade funcional de indivíduos idosos. Porém é importante salientar que a dosagem diária de vitamina $\mathrm{E}$ não deve atingir $400 \mathrm{IU}$. Estudos mostram que altas doses diárias de uso prolongado de vitamina $\mathrm{E}$ aumentam a incidência de mortalidade geral e em pacientes com doenças vasculares e diabetes mellitus, há aumento na incidência de falência cardiovascular (Boothby e Doering9 2005). Portanto o uso deve ser controlado, com dose diária recomendada de 30 IU (Pham e Plakogiannis ${ }^{23}$ 2005).

\section{Aspectos fisiológicos do envelhecimento}

O aumento dramático na expectativa de vida nos últimos 10 a 15 anos demanda que os clínicos estejam atentos às várias alteraçôes fisiológicas relevantes que ocorrem com a idade (Orr e Chen ${ }^{22}$ 2002). Devido às alteraçóes bioquímicas acumuladas ao longo da vida de um indivíduo, há alteraçôes fisiológicas comuns para a maioria dos idosos. Essas alteraçóes devem ser consideradas no manejo do paciente idoso, seja para a prescriçáo de medicamentos, para a indicação de exercícios físicos ou ainda para a adequaçáo da dieta.

Dentre as principais alterações fisiológicas que podem afetar o comportamento alimentício dos pacientes idosos, podemos evidenciar a diminuição da sensibilidade para os gostos primários, a perda parcial ou total dos elementos dentários, a desaceleração do metabolismo e a presença de doenças crônicas com consequente utilização de múltiplos medicamentos (Salgado ${ }^{25}$ 2002, Maracci $^{20}$ 1993).

É sabido que a maioria dos idosos apresenta alterações sensoriais, com declínio da visão, da audição, do olfato e da gustação (Bhutto e Morley ${ }^{6}$ 2008, Sies $^{27}$ 1995).

Principalmente os dois últimos afetam diretamente a 
Tramontino VS, Nuñez JMC, Takahashi JMFK, Santos-Daroz CB, Rizzatti-Barbosa CM. Nutrição para idosos. Revista de Odontologia da Universidade Cidade de São Paulo 2009 set-dez; 21(3): 258-67

nutrição desses indivíduos, uma vez que o alimento passa a ser menos apetitoso e desejado pelo idoso. Há uma relevante redução da sensibilidade para os gostos primários, tais como o doce, o salgado, o amargo e o ácido, grande parte causada pela redução dos botôes gustativos - que são diminuídos em até $60 \%$, se comparados aos de indivíduos adultos (Salgado ${ }^{25}$ 2002).

Dentre os fatores metabólicos, as alterações gastrintestinais, hepáticas e renais merecem destaque (Salgado ${ }^{25}$ 2002, Bhutto e Morley ${ }^{6}$ 2008). As alterações gastrintestinais ocorrem principalmente devido à alteração na estrutura e na função do estômago. Como consequência há diminuição da secreção salivar, redução da motilidade gástrica, queda na produção de suco e hormônios gástricos e enzimas digestivas, além de poder ocorrer diverticulite (Salgado ${ }^{25}$ 2002, Orr e Chen ${ }^{22}$ 2002), constipação intestinal e incontinência fecal (Bhutto e Morley ${ }^{6}$ 2008).

O resultado das alteraçóes gastrintestinais é a deficiente absorção dos nutrientes, como a vitamina D (Bhutto e Morley ${ }^{6}$ 2008), com consequente déficit na digestão, que se torna mais lenta e menos eficiente podendo também gerar mal-estar e flatulência. Para os indivíduos que não apresentaram alimentação adequada ao passar dos anos, há maior risco de problemas como diverticulite e constipação intestinal, que são resultado, sobretudo, de uma nutrição pobre em fibras alimentares. A redução da função hepática exige cautela no que diz respeito à ingestão de gorduras e outras substâncias que são excretadas por este órgão (Bhutto e Morley ${ }^{6}$ 2008). Da mesma forma, a diminuição da função renal sobrecarrega o mecanismo de excreção das proteínas, aspectos que devem ser observados nos sinais e sintomas dos idosos e adaptados quando necessário (Salgado 25 2002).

Uma particularidade dos idosos que náo pode ser ignorada é a reduzida tolerância à glicose. Isso provavelmente ocorre devido à diminuiçáo da produção hormonal e devido à alteração da composiçâo corporal dos idosos, que faz com que esses indivíduos apresentem maior proporção de células gordurosas frente às células musculares. A tolerância à glicose é reduzida, ou porque a secreçáo de insulina diante de uma carga de glicose encontra-se diminuída, ou porque o indivíduo apresenta uma resposta diminuída dos tecidos para a ação da insulina (Salgado ${ }^{25}$ 2002). Ao perceber esse problema no paciente idoso, é importante que se faça o diagnóstico diferencial do diabetes, uma vez que o tratamento da reduzida tolerância à glicose é realizado normalmente somente com adequação da dieta.

\section{Nutrição e saúde bucal}

A nutrição e a saúde bucal são dois fatores que se complementam. Um afeta diretamente o outro. Da mesma forma que a falta de dentes irá levar a uma mastigação comprometida e muitas vezes com declínio da qualidade nutricional, esse declínio nutricional irá levar a problemas bucais e à perda de mais dentes, formando assim um círculo vicioso e altamente prejudicial à saúde geral do idoso.

Dessa forma, é importante observar e identificar possíveis carências alimentares que possam trazer problemas bucais, evitando-se a perda de dentes; assim como orientar os pacientes parcial ou totalmente edêntulos sobre a importância de se adaptarem a uma dieta adequada, que seja possível de acordo com sua condição bucal e capacidade mastigatória. A função mastigatória pode ser restaurada por terapia protética adequada, que resulta em aumento na atividade dos músculos mastigatórios durante a mastigação, reduzindo-se o tempo e o número de movimentos até a deglutição (Budtz et al. ${ }^{10}$ 2001).

Dentre os problemas bucais mais comuns que podem ser agravados pela má alimentação, estão as cáries, a doença periodontal, a perda de dentes e a perda da integridade da mucosa. As cáries são agravadas sobretudo devido à dieta cariogênica (rica em açúcar) e à xerostomia, ocasionada em grande parte pelas avitaminoses. As doenças periodontais são mais frequentes quando há diminuição da resposta imunológica e da atividade fagocítica. Ambas as doenças, se náo controladas, fatalmente levam à perda de elementos dentários. A integridade da mucosa pode ser prejudicada em muitos casos de avitaminoses (Coelho ${ }^{11}$ 2004). No Quadro 1 estão descritos os principais sinais clínicos bucais associados a carências de vitaminas e minerais.

\section{Necessidades nutricionais do idoso}

A avaliação do estado nutricional do idoso é considerada complexa em razão da influência de uma série de fatores que necessitam ser investigados detalhadamente, visando diagnóstico nutricional acurado, que possibilite intervenção nutricional adequada. Alteraçôes fisiológicas, processos patológicos crônicos e situações individuais que ocorrem com o envelhecimento, geralmente interferem no estado nutricional do indivíduo (Sampaio ${ }^{26}$ 2004). Dessa forma as necessidades nutricionais do idoso devem ser particularizadas para cada caso, de acordo 
Tramontino VS, Nuñez JMC, Takahashi JMFK, Santos-Daroz CB, Rizzatti-Barbosa CM. Nutrição para idosos. Revista de Odontologia da Universidade Cidade de São Paulo 2009 set-dez; 21(3): 258-67

com as experiências de cada um. Dependem de diversos fatores como o estado geral de saúde, os níveis de atividade física, as alteraçóes na capacidade de mastigação, a capacidade digestiva e absorção de nutrientes, a eficiência metabólica, as alteraçóes no sistema endócrino, o estado emocional e a biodisponibilidade dos nutrientes. É necessário que a alimentação de qualidade seja combinada às condições físicas e psicológicas do paciente idoso, de forma a suprir suas necessidades (Hall e Wendin ${ }^{13}$ 2008).

A fim de identificar e suprir as necessidades individuais dos idosos, avaliaçóes nutricionais devem ser realizadas. Os métodos de avaliação mais comuns são o antropométrico, o inquérito dos hábitos alimentares e o bioquímico (Najas e Pereira ${ }^{21}$ 2002, Sampaio ${ }^{26} 2004$, Martins et al..$^{19}$ 1987, Acunã e Cruz ${ }^{1}$ 2004).

O método antropométrico é o mais utilizado para o manejo dos pacientes idosos, devido à sua facilidade de aplicação e à ótima correlação de seus resultados com a composição corporal do indivíduo (Najas e Pereira ${ }^{21}$ 2002). Esse método tem como fundamento a tomada de medidas como peso; altura; combinaçóes de altura e peso; medidas de dobras ou pregas cutâneas; circunferências do braço, da cintura e da panturrilha; comprimento de segmentos; largura óssea; compleição (Sampaio ${ }^{26}$ 2004, Najas e Pereira ${ }^{21}$ 2002, Acunã e Cruz ${ }^{1}$ 2004).

$\mathrm{O}$ inquérito dos hábitos alimentares tem como objetivo avaliar a qualidade e a quantidade dos alimentos consumidos diariamente, com base num auto-relato do paciente. $\mathrm{O}$ paciente é orientado a anotar num diário de dieta tudo o que consumiu durante o dia, incluindo água, balas, etc. Embora seja um método conclusivo, sua aplicação para pacientes idosos não é muito confiável, uma vez que esses pacientes por vezes apresentam perda de memória e analfabetismo (Najas e Pereira ${ }^{21}$ 2002, Acunâ e Cruz ${ }^{1}$ 2004).

O método bioquímico é o que apresenta resultados mais objetivos e confiáveis, uma vez que os resultados são obtidos através da análise de uma amostra de sangue do paciente. São investigadas, principalmente a albumina, o colesterol total e fraçóes, a transferrina, o hematócrito, a hemoglobina e a contagem de linfócitos (Sampaio ${ }^{26}$ 2004, Najas e Pereira ${ }^{21}$ 2002, Acunã e Cruz ${ }^{1}$ 2004). Por ser simples e muito preciso, o método bioquímico deve constar da avaliação geriátrica.

Assim sendo, com o intuito de determinar riscos nutricionais em idosos, antes que as alterações clínicas pudessem ser manifestadas e a fim de promover uma vi- gilância nutricional para reduzir hospitalizações e melhorar a qualidade de vida desses pacientes, foi criada a Miniavaliação Nutricional (Coelho ${ }^{11}$ 2004, Acunã e Cruz $^{1}$ 2004)

A Miniavaliação Nutricional deve constar da avaliaçáo geriátrica, é composta por medidas e questóes práticas e é dividida em quatro partes: as medidas antropométricas (circunferências, peso, altura e história de perda de peso), a avaliação global (estilo de vida, medicamentos, mobilidade e doenças), a avaliação dietética (qualitativa e quantitativa) e uma autoavaliaçáo (autopercepção de sua saúde e qualidade nutricional) (Coelho ${ }^{11}$ 2004, Acunâ e Cruz ${ }^{1}$ 2004).

Se, em algum método de avaliação for detectado o risco ou a efetiva presença de desnutrição, métodos simples como a orientação e a adaptação da dieta devem ser prontamente inseridos. A suplementaçáo nutricional por meio de comprimidos deve ser realizada em casos mais avançados, de acordo com o sintoma apresentado.

No Quadro 2, encontram-se as principais vitaminas e minerais para o funcionamento do organismo humano, suas fontes, funçóes e os problemas decorrentes de uma avitaminose.

De uma forma geral, as necessidades energéticas do indivíduo idoso são menores que as dos indivíduos jovens. Isso é devido à diminuição da taxa metabólica basal, que em parte pode ser explicada pela alteração da composição corporal do idoso, com redução da massa muscular e aumento da massa gordurosa. Acredita-se que $30 \mathrm{kcal} / \mathrm{kg} /$ dia sejam suficientes para a manutenção dos gastos calóricos da pessoa idosa em atividade regular (Marchini et al. ${ }^{18}$ 1998). Porém, em situaçóes em que ocorre trauma orgânico (cirurgias, infecçôes, politraumatismos, etc.) podem aumentar as necessidades de um nutriente específico na razão de 1,5 a 3 vezes o basal.

Com relação ao consumo de carboidratos, a indicação para pacientes idosos, de uma forma geral, é que estes componham $60 \%$ das necessidades diárias de energia (Salgado ${ }^{25}$ 2002, Marchini et al. ${ }^{18}$ 1998). Porém a qualidade desses carboidratos deve ser acompanhada de perto: deve-se priorizar o consumo de carboidratos complexos e fibras para a prevenção e controle de doenças cardiovasculares, constipação intestinal, câncer do cólon e diabete mellitus e diminuir o uso de açúcar (sacarose), evitando problemas decorrentes da redução da tolerância à glicose (Salgado ${ }^{25}$ 2002, Marchini et al. ${ }^{18}$ 1998).

O consumo de proteínas, para idosos saudáveis, deve preencher $15 \%$ das necessidades calóricas diárias do in- 
divíduo (Salgado ${ }^{25}$ 2002). Essa é a mesma porcentagem indicada a indivíduos jovens, já que não há evidências de que o envelhecimento altera as necessidades proteicas. A quantidade recomendada é fixada entre $0,8 \mathrm{~g}$ de proteína por $\mathrm{kg}$ de peso corporal ao dia (Marchini et al. ${ }^{18} 1998$ ).

A recomendação diária para os lipídeos é de $25 \%$ das necessidades energéticas. Deve-se controlar o consumo exagerado dessas substâncias devido a sua alta correlação com desordens cardiovasculares e câncer. Sem removê-las completamente da dieta. No manejo do paciente idoso a gordura tem papel destacado por tornar o alimento mais palatável, diminuindo a incidência de anorexia entre esses pacientes (Marchini et al. ${ }^{18}$ 1998). É importante que seja reduzido o consumo de gordura saturada, substituindo-o pela gordura insaturada, que é mais saudável e também pelos ácidos graxos poli-insaturados (Salgado ${ }^{25}$ 2002, Marchini et al. ${ }^{18}$ 1998).

Os micronutrientes são recomendados da mesma forma que para adultos jovens, desde que o idoso esteja saudável e possua bons hábitos alimentares. Nos casos de avitaminoses, deve-se recomendar a alteração correspondente na dieta e/ou optar por suplementação vitamínica e de minerais. Os suplementos, como os polivitamínicos para os casos de desnutrição, são facilmente encontrados em farmácias, assim como as vitaminas e os minerais específicos, como o cálcio, para os casos de osteoporose, o zinco, para a melhora do sistema imunológico, o selênio e as vitaminas $\mathrm{C}$ e E, com efeito antioxidante (Salgado ${ }^{25}$ 2002).

A mínima ingestão diária de água para indivíduos idosos deve ser de $30 \mathrm{ml}$ por $\mathrm{kg}$ de peso corporal. Essa dose diária é importante para evitar a desidratação, situação muito comum entre os idosos. A desidratação leva à desarmonia do funcionamento do organismo, além de intensificar a hipertensão, elevar a temperatura corporal, aumentar a susceptibilidade a constipaçóes, provocar náuseas, secura das mucosas, diminuição na excreção da urina e ainda levar à confusão mental (Salgado ${ }^{25}$ 2002).

\section{CONCLUSÕES}

Os resultados de uma vida saudável ou de excessos são colhidos na velhice. A qualidade do envelhecimento é resultado do estilo de vida pelo qual o indivíduo optou, sendo os hábitos alimentares responsáveis por grande parcela da qualidade dessa etapa vivida. A alimentação adequada pode levar a uma velhice saudável, com maior capacidade funcional e menor incidência de doenças. Dessa forma, o acompanhamento da alimentação por profissionais da saúde, através da identificação de possíveis riscos ou de erros alimentares já instalados e a consequente orientação para uma nutrição adequada, adaptada às condiçóes de cada indivíduo idoso, devem ser constantes. Para que a vida longa, desejada por todos, seja prazerosa e náo onerosa. 
Tramontino VS, Nuñez JMC, Takahashi JMFK, Santos-Daroz CB, Rizzatti-Barbosa CM. Nutrição para idosos. Revista de Odontologia da Universidade Cidade de São Paulo 2009 set-dez; 21(3): 258-67

Quadro 1. Principais sinais clinicos bucais associados a carências de vitaminas e minerais.

\begin{tabular}{|c|c|}
\hline Vitamina/Mineral & Consequências relevantes da carência na área odontológica \\
\hline Vit. A & $\begin{array}{l}\text { Prejuízo no reparo dos tecidos, descamação da mucosa, queratose da mucosa, aumento do } \\
\text { risco de candidíase, hipertrofia gengival e inflamação, leucoplasia, diminuição do paladar, } \\
\text { xerostomia e hipoplasia em dentes maduros. }\end{array}$ \\
\hline Vit. C & $\begin{array}{l}\text { Leve: Resposta tecidual exagerada, maior risco de infecção, fragilidade dos vasos sanguíne- } \\
\text { os, aumento dos sinais e sintomas periodontais, cicatrização lenta. Severa: escorbuto. }\end{array}$ \\
\hline Vit. K & Aumento no risco de sangramento e candidíase \\
\hline Vit. D & $\begin{array}{l}\text { Regeneração óssea anormal, osteoporose, calcificação incompleta dos dentes e do osso } \\
\text { alveolar, osteomalácia, raquitismo. }\end{array}$ \\
\hline Vit. & $\begin{array}{l}\text { Complexo B Queilite angular dos lábios, leucoplasia, ardor da língua, atrofia papilar, } \\
\text { língua magenta, fissuras, glossite. }\end{array}$ \\
\hline Vit. B2 & $\begin{array}{l}\text { Queilite angular, atrofia das papilas filiformes, papilas fungiformes aumentadas, lábios } \\
\text { vermelhos brilhantes, língua magenta, língua dolorida. }\end{array}$ \\
\hline Vit. B3 & $\begin{array}{l}\text { Queilite angular, mucosite, estomatite, dor oral, ulceração, língua desnuda, glossite, glosso- } \\
\text { dinia, gengivite ulcerativa. Ácido Fólico Queilite angular, mucosite, estomatite, sensibili- } \\
\text { dade ou queimação da boca, aumento no risco de candidíase, gengiva inflamada, glossite, } \\
\text { úlceras aftosas. }\end{array}$ \\
\hline Vit. B6 & Queilite angular, dor e queimação da boca, glossite e glossodinia \\
\hline Vit. B12 & $\begin{array}{l}\text { Queilite angular, dor e queimação da boca, mucosite/estomatite, gengiva hemorrágica, } \\
\text { halitose, displasia epitelial da mucosa oral, parestesia oral, deslocamento de fibras perio- } \\
\text { dontais, distorção do paladar, glossite, cicatrização lenta, xerostomia, perda óssea, úlceras } \\
\text { aftosas. }\end{array}$ \\
\hline Fluoreto & Diminuição da resistência a cáries dentárias. \\
\hline Ferro & $\begin{array}{l}\text { Queilite angular, palidez dos lábios e mucosa bucal, dor e queimação da língua, atrofia/ } \\
\text { desnudamento de papilas filiformes, glossite, maior risco de candidíase. }\end{array}$ \\
\hline Cálcio & $\begin{array}{l}\text { Calcificação incompleta dos dentes, raquitismo, osteomalácia, reabsorção óssea excessiva, } \\
\text { fragilidade óssea, osteoporose, maior tendência à hemorragia, aumento da mobilidade do } \\
\text { dente e perda prematura. }\end{array}$ \\
\hline Cobre & $\begin{array}{l}\text { Redução das trabéculas do osso alveolar, diminuição da vascularização dos tecidos, maior } \\
\text { fragilidade tecidual. }\end{array}$ \\
\hline Zinco & $\begin{array}{l}\text { Perda ou distorção do sentido de paladar e olfato, perda da sensibilidade de língua, cica- } \\
\text { trização lenta, prejuízo da queratinização e espessamento das células epiteliais, atrofia da } \\
\text { mucosa bucal, maior susceptibilidade à doença periodontal e candidíase, xerostomia. }\end{array}$ \\
\hline Magnésio & Fragilidade do osso alveolar, hipertrofia gengival. \\
\hline Fósforo & $\begin{array}{l}\text { Calcificação incompleta dos dentes, susceptibilidade à doença periodontal devido aos } \\
\text { efeitos sobre o osso alveolar. }\end{array}$ \\
\hline
\end{tabular}

Fonte: Coelho AK In: Odontogeriatria; Eliana Campostrini, Editora Revinter, 1a Edição, 2004. Pp 43-44. 
Quadro 2. Principais vitaminas e minerais, suas fontes, funçôes e sintomas de avitaminose.

\begin{tabular}{|c|c|c|c|}
\hline Vitamina & Fontes & Funçóes & Avitaminose \\
\hline A & $\begin{array}{l}\text { Fígado de aves e animais, } \\
\text { cenoura, brócolis, escarola }\end{array}$ & $\begin{array}{l}\text { Combate os radicais livres, } \\
\text { atua na formação dos ossos, } \\
\text { pele e em funçóes da retina }\end{array}$ & $\begin{array}{l}\text { Problemas visuais, secura da } \\
\text { pele, diminuição dos glóbulos } \\
\text { vermelhos, cálculos renais }\end{array}$ \\
\hline $\mathrm{C}$ & $\begin{array}{l}\text { Laranja, limão, abacaxi, kiwi, } \\
\text { acerola, morango, brócolis, } \\
\text { manga }\end{array}$ & $\begin{array}{l}\text { Fortalece o sistema imunoló- } \\
\text { gico, combate radicais livres, } \\
\text { aumenta a absorção do ferro }\end{array}$ & Escorbuto \\
\hline $\mathrm{E}$ & $\begin{array}{l}\text { Cereais integrais, verduras, } \\
\text { azeite e vegetais }\end{array}$ & $\begin{array}{l}\text { Antioxidante, atua na forma- } \\
\text { ção de células sexuais }\end{array}$ & $\begin{array}{l}\text { Dificuldades visuais, altera- } \\
\text { ções neurológicas, esterilidade }\end{array}$ \\
\hline $\mathrm{K}$ & Fígado e verduras & $\begin{array}{l}\text { Atua na coagulação do san- } \\
\text { gue, previne osteoporose }\end{array}$ & $\begin{array}{l}\text { Desnutrição, má função do } \\
\text { fígado, problemas intestinais }\end{array}$ \\
\hline B1 & $\begin{array}{l}\text { Cereais, carnes, verduras, } \\
\text { levedo de cerveja }\end{array}$ & $\begin{array}{l}\text { Atua no metabolismo energé- } \\
\text { tico dos açúcares }\end{array}$ & Beribéri \\
\hline $\mathrm{B} 2$ & Leites, carnes, verduras & $\begin{array}{l}\text { Atua no metabolismo de enzi- } \\
\text { mas, e na proteção do sistema } \\
\text { nervoso }\end{array}$ & $\begin{array}{l}\text { Inflamaçóes na língua, ane- } \\
\text { mias, seborreia }\end{array}$ \\
\hline B5 & $\begin{array}{l}\text { Fígado, cogumelos, milho, } \\
\text { abacate, ovos, leite, vegetais }\end{array}$ & $\begin{array}{l}\text { Metabolismo de proteínas, } \\
\text { gorduras e açúcares }\end{array}$ & $\begin{array}{l}\text { Fadigas, cãibras musculares, } \\
\text { insônia }\end{array}$ \\
\hline B6 & $\begin{array}{l}\text { Carnes, frutas, verduras e } \\
\text { cereais }\end{array}$ & $\begin{array}{l}\text { Atua no crescimento, na pro- } \\
\text { teção celular, no metabolismo } \\
\text { de gorduras e proteínas e na } \\
\text { produção de hormônios }\end{array}$ & $\begin{array}{l}\text { Seborreia, anemia, distúrbios } \\
\text { de crescimento }\end{array}$ \\
\hline $\mathrm{B} 12$ & Fígado, carnes & $\begin{array}{l}\text { Formação de hemácias e } \\
\text { multiplicação celular }\end{array}$ & Anemia perniciosa \\
\hline B3 & $\begin{array}{l}\text { Ervilha, amendoim, fava, } \\
\text { peixe, feijão, fígado }\end{array}$ & $\begin{array}{l}\text { Manutenção da pele, prote- } \\
\text { ção do fígado, regula a taxa de } \\
\text { colesterol no sangue }\end{array}$ & $\begin{array}{l}\text { Insônia, dor de cabeça, der- } \\
\text { matite, diarreia, depressão }\end{array}$ \\
\hline B9 & Cogumelos, hortaliças verdes & $\begin{array}{l}\text { Metabolismo dos aminoáci- } \\
\text { dos, formação das hemácias e } \\
\text { dos tecidos nervosos }\end{array}$ & $\begin{array}{l}\text { Anemia megaloblástica, doen- } \\
\text { ças do tubo neural }\end{array}$ \\
\hline $\mathrm{D}$ & $\begin{array}{l}\text { Óleo de peixe, fígado, gema } \\
\text { de ovos }\end{array}$ & $\begin{array}{l}\text { Regulação do cálcio do san- } \\
\text { gue e dos ossos }\end{array}$ & Raquitismo e osteoporose \\
\hline
\end{tabular}

Fonte: Toda Biologia.com. http://www.todabiologia.com/saude/vitaminas.htm. Acesso em 02/08/2008. 


\section{REFERÊNCIAS}

1. Acuña K, Cruz T. Avaliação do estado nutricional de adultos e idosos e situação nutricional da população brasileira. Arq Bras Endocrinol Metab. 2004; 48(3):345361.

2. Almada-Filho CM. Antioxidantes e radicais livres. In: Freitas, Py, Neri, Cançado, Gorzoni, Rocha. Tratado de geriatria e gerontologia. Rio de Janeiro: Guanabara Koogan, 2002. p. 744-748.

3. Ames JM. Mass spectrometry to detect the site specificity of advanced glycation/lipoxidation endproduct formation on protein: some challenges and solutions. Biochem Soc Trans. 2008;36(Pt5):1051-4.

4. Ashok BT, Ali R. The aging paradox: free radical theory of aging. Exp Gerontol. 1999; 34(3):293-303.

5. Barroso CCM. Considerações sobre nutrição para idosos. In: Mello, HSA. Odontogeriatria. São Paulo: Santos, 2005. p. 15-30.

6. Bhutto A, Morley JE. The clinical significance of gastrointestinal changes with aging. Curr Opin Clin Nutr Metab Care. 2008; 11(5):651-60.

7. Bianchi MLP, Antunes LMG. Free radicals and the main dietary antioxidants. Rev Nutr. 1999; 12(2):123130.

8. Biesalski HK. Free radical theory of aging. Curr Opin Clin Nutr Metab Care. 2002; 5(1):5-10.

9. Boothby LA, Doering PL. Vitamin C and vitamin E for Alzheimer's disease. Ann Pharmacother. 2005; 39(12):2073-80.

10. Budtz-Jorgensen E, Chung JP, Rapin CH. Nutrition and oral health. Best Pract Res Clin Gastroenterol. 2001; 15(6):885-96.

11. Coelho, AK. Nutrição e Saúde Bucal. In: Campostrini E. Odontogeriatria. Rio de Janeiro: Revinter, 2004. cap.7, p. 38-67.

12. Guimarães RM. Terapias antienvelhecimento. In: Freitas, Py, Neri, Cançado, Gorzoni, Rocha. Tratado de geriatria e gerontologia. Rio de Janeiro: Guanabara Koogan, 2002. p. 749-753.

13. Hall G, Wendin K. Sensory design of foods for the elderly. Ann Nutr Metab. 2008; 52(1):25-8.
14. Hayashi Y, Yoshida M, Yamato M, Ide T, Wu Z, Ochi-Shindou M, et al. Reverse of age-dependent memory impairment and mitochondrial DNA damage in microglia by an overexpression of human mitochondrial transcription factor a in mice. J Neurosci. 2008; 28(34):8624-34.

15. Khaw KT, Bingham S, Welch A, Luben R, Wareham N, Oakes S, Day N. Relation between plasma ascorbic acid and mortality in men and women in EPICNorfolk prospective study: a prospective population on study. Lancet, 2001;357: 657-663.

16. Knight JA. The biochemistry of aging. Adv Clin Chem. 2000;35:1-62.

17. Lonn EM, Yusuf S. Is there a role for antioxidant vitamins in the prevention of cardiovascular disease? An uptade on epidemiological and clinical trials data. Can J Cardiol. 1997; 13(10):957-65.

18. Marchini JS, Ferrioli E, Moriguti JC. Suporte nutricional no paciente idoso: definição, diagnóstico, avaliação e intervenção. Medicina, Ribeirão Preto, 1998; 31:54-61.

19. Martins RL, Addison E, Valente FLS. Caracterização nutricional preliminar dos pacientes internados no Hospital Universitário da Universidade Federal de Santa Catarina. Rer Ciênci Saúde 1986/1987; 516(112):87- 104.

20. Marucci MFN. Equilíbrio nutricional na terceira idade. In: Congresso Nacional, Alimentos e equilíbrio nutricional: Perspectivas para o século XXI, 3, São Paulo, 1993. Anais, Sociedade Brasileira de Alimentação e Nutrição, 1993, p.35-36.

21. Najas, M e Pereira AI. Nutrição. In: Freitas, Py, Neri, Cançado, Gorzoni, Rocha. Tratado de Geriatria e Gerontologia, Rio de Janeiro: Guanabara Koogan, 2002, cap. 101, p. 838-845.

22. Orr WC, Chen CL. Aging and neural control of the GI tract: IV. Clinical and physiological aspects of gastrointestinal motility and aging. Am J Physiol Gastrointest Liver Physiol. 2002; 283(6):G1226-31. 266 
23. Pham DQ, Plakogiannis R. Vitamin E supplementation in Alzheimer's disease, Parkinson's disease, tardive dyskinesia, and cataract: Part 2. Ann Pharmacother. 2005; 39(12):2065-72.

24. Sahni S, Hannan MT, Gagnon D, Blumberg J, Cupples LA, Kiel DP, et al. High vitamin C intake is associated with lower 4-year bone loss in elderly men. J Nutr. 2008; 138(10):1931-8.

25. Salgado JM. Nutrição na terceira idade. In: Brunetti, RF, Montenegro FLB. Odontogeriatria: noções e conceitos de interesse clínico. São Paulo: Artes Médicas, 2002. p. 62-70.

26. Sampaio LR. Avaliação nutricional e envelhecimento. Rev Nutr. 2004; 17(4): 507-514.
27. Sies H, Stahl W. Vitamins E and C, beta-carotene and other carotenoids as antioxidants. American Journal of Clinical Nutrition, Bethesda. 1995; 62(6):13151321.

28. Toda Biologia.com. Tabela das principais vitaminas. Disponível em: http:/ /www. todabiologia.com/saude/vitaminas.htm [Acesso em 02/08/2008].

29. Vanitallie TB. Parkinson disease: primacy of age as a risk factor for mitochondrial dysfunction. Metabolism. 2008; 57(Suppl 2): S50-5.

30. Weber CA, Ernst ME. Antioxidants, supplements and Parkinson's disease. Ann Pharmacother. 2006; 40(5):935-8.

31. Wenzel U. Nutrition, sirtuins and aging. Genes Nutr. 2006;1(2):85-93.

Recebido em: 9/2/2008

Aceito em: 1/10/2009 